Shin-Chuan Hwang

Taiwan Banana Research Institute, Pingtung, Taiwan

Wen-Hsiung Ko

University of Hawaii at Manoa, Hilo, HI

\title{
Cavendish Banana Cultivars Resistant to Fusarium Wilt Acquired through Somaclonal Variation in Taiwan
}

Fusarium wilt of banana (Musa spp.), caused by Fusarium oxysporum Schlechtend.:Fr. f. sp. cubense (E.F. Smith) Snyder \& Hansen, was first reported from Panama as early as 1890 and thus has been commonly known as Panama disease (23). The disease is widespread in banana-growing regions of Asia, Africa, Australia, and the tropical Americas, and is one of the most catastrophic plant diseases in the world, destroying more than 40,000 ha of banana in Central and South America over a period of 50 years.

Prior to 1967, there were only three races of $F$. oxysporum f. sp. cubense on members of Musaceae. Race 1 attacks Gros Michel, the favorite commercial banana cultivar for world trade in many countries. For more than 60 years, it was the most serious problem in banana cultivation in tropical America. The disease was under control only after the replacement of the susceptible Gros Michel with the resistant Cavendish banana cultivar in the 1960s (23). Race 2 affects only the hybrid triploid Bluggoe (ABB), while race 3 attacks Heliconia spp. and is nonpathogenic or weakly pathogenic on Musa spp. (24).

\section{Banana Production in Taiwan}

The oldest international banana trade in Asia began in the early 1900s in Taiwan, where bananas were produced for exporting to neighboring Japan. The banana industry, involving mostly small producers, expanded rapidly and reached peak production on over 50,000 ha in the mid1960s, ranking Taiwan as one of the largest banana exporting countries in the world, second only to Ecuador (21). The industry began to decline in the early 1970s due to

Dr. Ko's address is: Department of Plant and Environmental Protection Sciences, Beaumont Agricultural Research Center, University of Hawaii at Manoa, Hilo, Hawaii 96720. E-mail: kowh@hawaii.edu

Publication no. D-2004-0409-01F

(C) 2004 The American Phytopathological Society high labor cost and foreign competition. During the last decade, only around 5,000 ha have remained in production. However, because bananas produced in Taiwan's subtropical climate are excellent in eating quality, they are still highly prized in the Japanese market.

During growth, each banana plant produces several shoots from the rhizome. The plant dies after harvest, and one or two shoots are allowed to grow and fruit. This ratoon cropping system is practiced in most banana producing countries. However, in Taiwan, most bananas are replanted every year so that fruit production coincides with spring export season and to reduce the risk of typhoon damage during the summer and fall. Cavendish is the most common banana cultivar cultivated in Taiwan, grown on more than $90 \%$ of hectares.

\section{A New Race Attacking the Resistant Cavendish}

The first instance of Fusarium wilt on the Cavendish cultivar in Taiwan was noticed in 1967 in the main banana producing area of southern Taiwan. The pathogen was found to be different from races 1,2 , and 3 in the range of hosts within the
Musaceae, and was designated race 4 of $F$. oxysporum f. sp. cubense (25). The disease spread rapidly, and the number of affected plants increased from one to 5,536 within 3 years (Fig. 1). In 1976, approximately 1,200 ha representing 500,000 banana plants were affected (26). New land was added for banana production each year, keeping production losses due to the disease about the same each year until new resistance could be found.

In principle, the morphological characteristics of races within the same forma specialis are indistinguishable. Race 4 of $F$. oxysporum f. sp. cubense from Taiwan, however, is unique in that on modified Komada's medium it forms laciniate colonies distinct from those of races 1 and 2 $(26,28)$. Six formae specialis of $F$. oxysporum, one saprophytic $F$. oxysporum, and three other species of Fusarium failed to form laciniate colonies on this medium, while every isolate of $F$. oxysporum f. sp. cubense obtained from more than 250 wilted Cavendish plants collected from different locations in Taiwan formed similar laciniate colonies (28). Recently, subtropical and tropical variants of race 4 have been described (19).

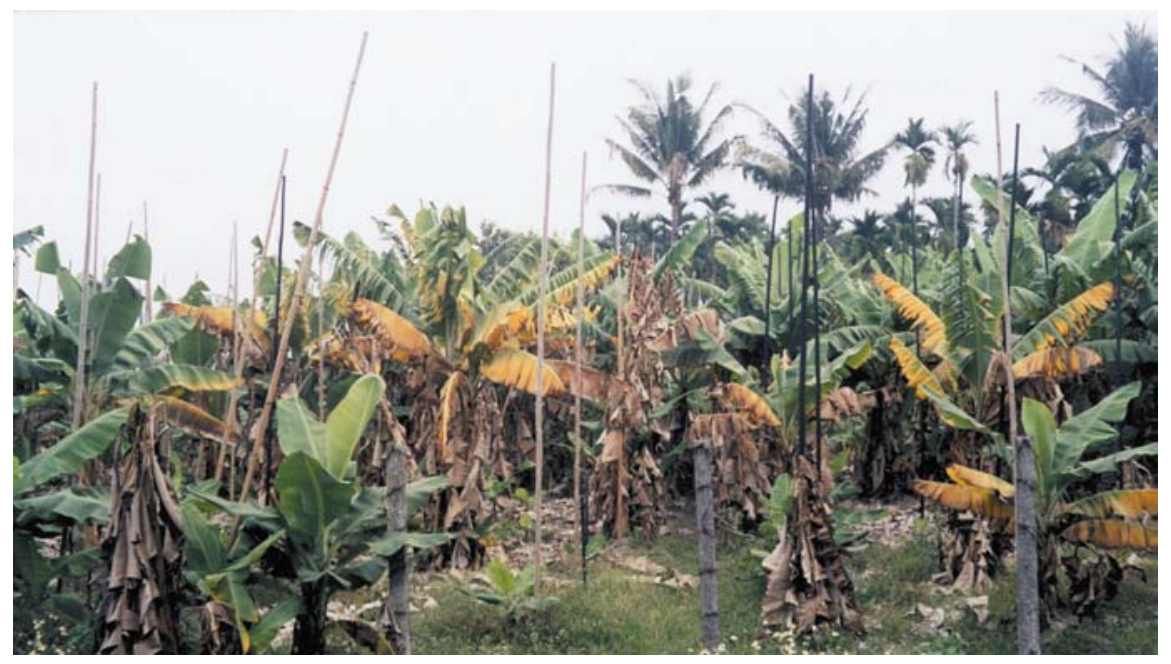

Fig. 1. Giant Cavendish banana orchard affected by Fusarium wilt. 


\section{Occurrence of the Disease Worldwide}

Since the first report of the appearance of race 4 of $F$. oxysporum $\mathrm{f}$. sp. cubense from Taiwan (25), Fusarium wilt of Caven-

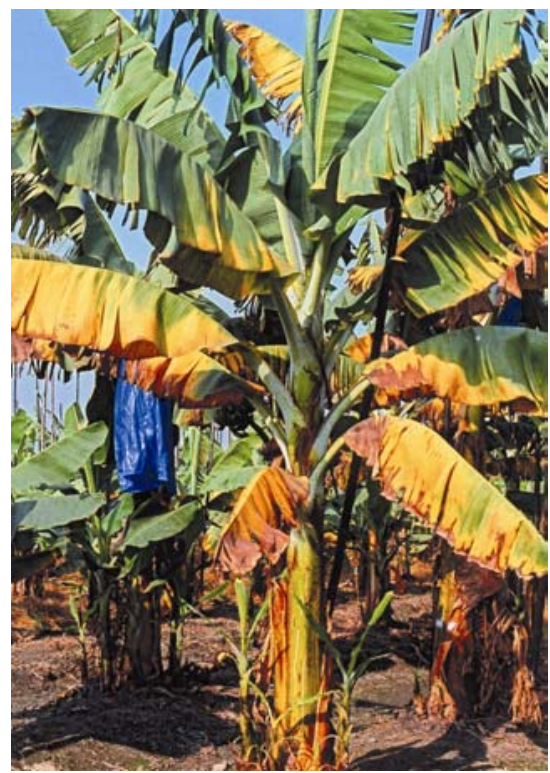

Fig. 2. Diseased Giant Cavendish banana plant with conspicuous yellowing symptoms on the lower leaves. dish cultivars has been reported in a number of places in the Eastern Hemisphere. Fusarium wilt in Cavendish banana was reported in the Canary Islands in the 1920s (1). Approximately 50 years later, R. H. Stover sent isolates of $F$. oxysporum $\mathrm{f}$. sp. cubense from diseased Cavendish plants in the Canary Islands and Philippines to Taiwan for identification. These isolates caused typical Fusarium wilt symptoms on Cavendish plantlets and were therefore identified as race 4 (26). Race 4 Fusarium wilt is the most serious problem of banana production in the Canary Islands $(18,21)$. However, the disease appeared to be localized and not serious in commercial Cavendish plantations in the Philippines (15).

Prior to 1976, Fusarium wilt had been observed sporadically on Cavendish cultivars in southern Queensland, Australia. The disease was not considered important there until the early 1980s, when its incidence and severity increased alarmingly. During that period of time, Fusarium wilt was known in more than 40 Cavendish plantations and subsequently spread to the nearby Byron Bay in northern New South Wales (18). In the Northern Territory of Australia, Fusarium wilt on Cavendish cultivars was found in 1997. Two further outbreaks were detected in 1998 and 1999 (3).
Fusarium wilt on Cavendish plants was observed in the province of Natal of South Africa as early as 1940 (18). The next outbreaks in Natal occurred in 1957, and since 1966, there have been regular reports of new outbreaks in this province. The disease had been present in the province of Transvaal since at least 1970 , and by the mid-1970s the disease was recognized as a major threat to banana production in that part of South Africa (18).

Fusarium wilt is a major disease that limits the commercial production of Cavendish banana in Malaysia. In the early 1990s, tissue-cultured plantlets of Cavendish cv. Grande Naine that were free from F. oxysporum f. sp. cubense were planted in a 349-ha farm in Nam Heng Estate. Although the area did not have any prior history of Fusarium wilt, the disease was detected 6 months after planting. Spread of the disease increased exponentially to $32.2 \%$ after 4 years (14). Similar outbreaks of Fusarium wilt occurred in another Cavendish farm in Johor, also without prior Fusarium wilt history. This suggests that race 4 of $F$. oxysporum $\mathrm{f}$. sp. cubense is probably indigenous to Southeast Asia. This region is also considered to be the center of origin of edible banana (22).

Fusarium wilt has devastated recently established Cavendish plantations in

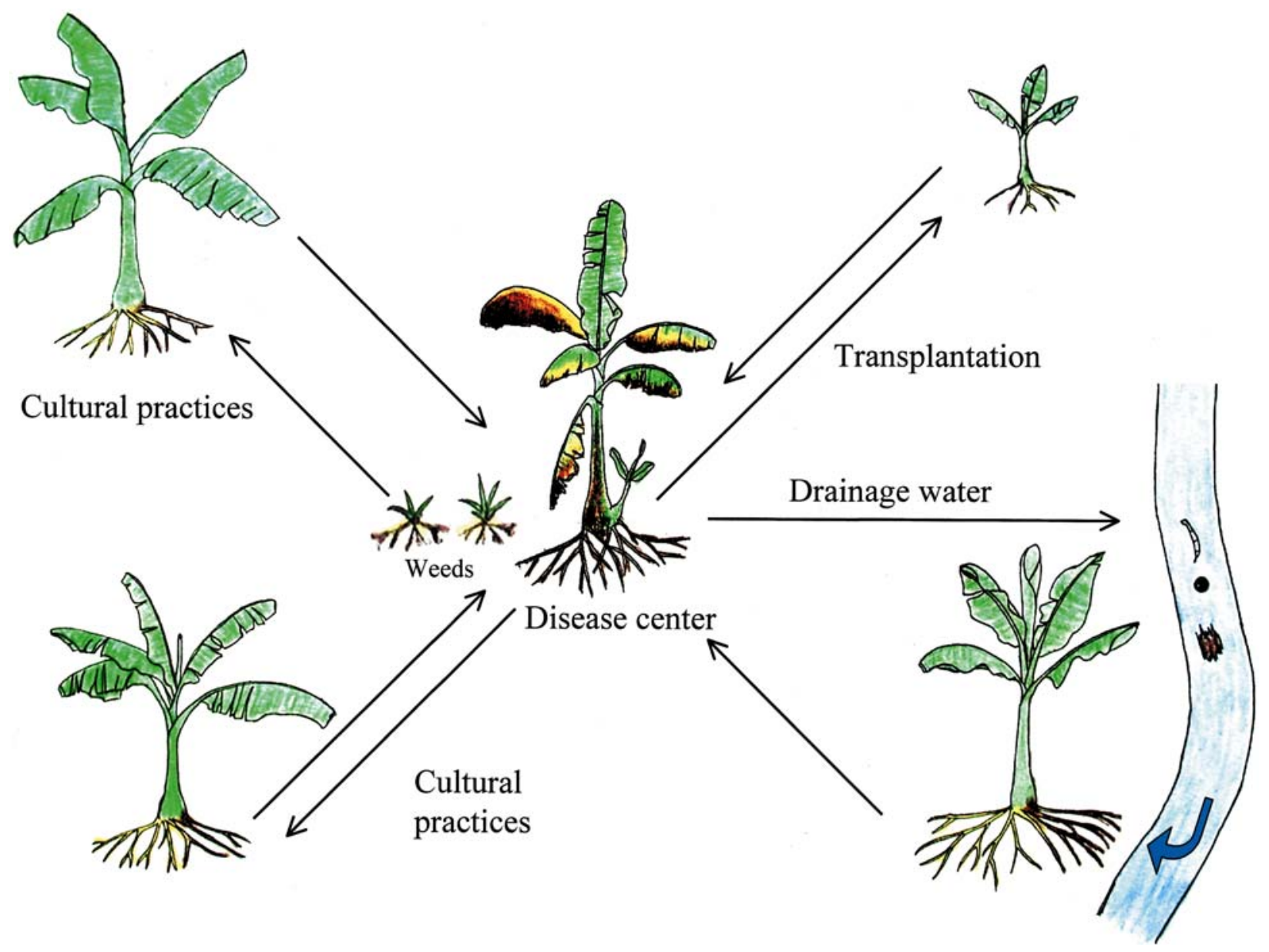

Fig. 3. Disease cycle of Fusarium wilt of banana caused by Fusarium oxysporum f. sp. cubense. 
Table 1. Disease incidences ${ }^{\mathrm{a}}$ of banana plants developed from suckers produced by resistant clones of Giant Cavendish

\begin{tabular}{|c|c|c|c|c|c|c|}
\hline \multirow[b]{2}{*}{ Clone } & \multicolumn{2}{|c|}{ First generation } & \multicolumn{2}{|c|}{ Second generation } & \multicolumn{2}{|c|}{ Third generation } \\
\hline & $\begin{array}{c}\text { No. of plants } \\
\text { tested }\end{array}$ & $\begin{array}{c}\text { Disease } \\
\text { incidence }(\%)\end{array}$ & $\begin{array}{l}\text { No. of plants } \\
\text { tested }\end{array}$ & $\begin{array}{c}\text { Disease } \\
\text { incidence }(\%)\end{array}$ & $\begin{array}{l}\text { No. of plants } \\
\text { tested }\end{array}$ & $\begin{array}{c}\text { Disease } \\
\text { incidence }(\%)\end{array}$ \\
\hline GCTCV-40 & 12 & 0 & 38 & 0 & 291 & 1.4 \\
\hline GCTCV-44 & 5 & 0 & 20 & 5.0 & 98 & 1.0 \\
\hline GCTCV-46 & 9 & 0 & 43 & 5.0 & 216 & 0.5 \\
\hline GCTCV-53 & 2 & 0 & 9 & 0 & 173 & 0.6 \\
\hline GCTCV-62 & 3 & 0 & 4 & 0 & 33 & 9.1 \\
\hline GCTCV-119 & 1 & 0 & 2 & 0 & 72 & 0 \\
\hline Parent & 50 & 60.0 & 50 & 74 & 107 & 39.3 \\
\hline
\end{tabular}

${ }^{a}$ Disease incidences were determined 1 year after planting.

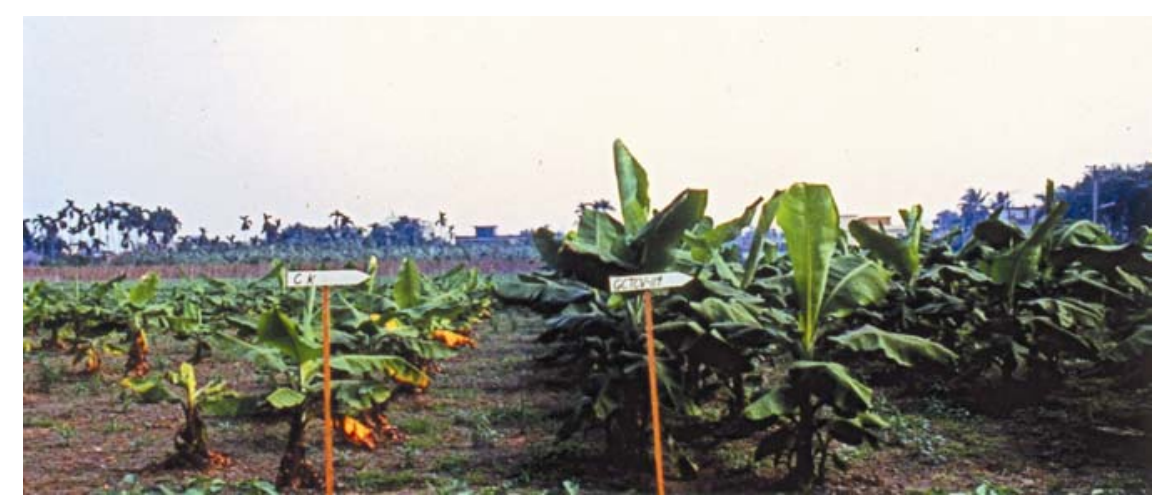

Fig. 4. Disease nursery with a resistant somaclone GCTCV-119 (right) and the parental Giant Cavendish (left).

Sumatra, Java, and Halmahera islands of Indonesia (2,16). The disease also has moved eastward to Papua New Guinea (4). In the early 1990s, a commercial plantation of the Cavendish cv. Valery was established on a 2,000-ha forested land in southern Sumatra. Bananas produced from this plantation were mainly for export to Japan and the Mideast. Fusarium wilt appeared a few months after planting of this cultivar. The incidence and severity of the disease increased dramatically. Much of the banana production in this plantation was destroyed by 1996 . However, the production of banana in the same plantation has increased slowly but steadily since 1998 , when resistant clone GCTCV-119 developed at the Taiwan Banana Institute was used for planting. This clone has maintained its Fusarium wilt resistant characteristics in the new environments. It is currently planted in about 800 ha of the infested land for local markets, and more may be planted for export in the future.

The information concerning the severity and distribution of race 4 of $F$. oxysporum f. sp. cubense in China is scant and incomplete. According to a brief report, Fusarium wilt on Xiangjiao (AAA) was found in Guangdong province in southern China in 1996 (20). Since Xiangjiao is a general term for edible bananas in the Chinese language, it is not known if the affected banana plants belong to a Cavendish cultivar. A research progress report from the Institute of Plant Protection, Guangdong
Academy of Agricultural Science posted in the Chinese internet in 2003 stated that about 50 ha in three banana production areas in Guangdong were affected by Fusarium wilt, with incidence ranging from 10 to $60 \%$. Based on colony morphology on modified Komada's medium (28) and pathogenicity tests with several banana cultivars including an unidentified cultivar from Taiwan, the pathogen was identified as race 4 of $F$. oxysporum f. sp. cubense. Currently, it is not clear if Cavendish Fusarium wilt is present in other banana producing provinces in southern China. The suspected presence of the disease in Guangxi province (30) awaits confirmation.

\section{Symptoms and Disease Cycle}

The first symptom is yellowing of lower leaves, which usually begins to appear 5 months after planting in Taiwan. The color stands out so conspicuously that the disease has been called "yellow leaf disease" locally (Fig. 2). In a diseased orchard, the number of plants with the yellowing symptom increases greatly after the emergence of the inflorescences, and the highest disease incidence occurs right before harvest (25). Leaf yellowing begins along the margin and advances toward the midribs. The leaf subsequently develops brown spots, and the petiole turns brown and buckles. Yellowing and buckling progress from older to younger leaves, and the entire plant dies. Infected plants frequently de-
Table 2. Disease incidences ${ }^{\mathrm{a}}$ of banana plants developed from plantlets produced by tissue cultures of second generation resistant clones of Giant Cavendish and planted on five infected banana farms

\begin{tabular}{lcc}
\hline Clone & $\begin{array}{c}\text { No. of } \\
\text { plants } \\
\text { tested }\end{array}$ & $\begin{array}{c}\text { Disease } \\
\text { incidence } \\
\mathbf{( \% )}\end{array}$ \\
\hline GCTCV-40 & 965 & 0.3 \\
GCTCV-44 & 50 & 0 \\
GCTCV-46 & 593 & 0.5 \\
GCTCV-53 & 467 & 3.9 \\
GCTCV-62 & 45 & 11.1 \\
GCTCV-119 & 45 & 2.2 \\
Parent & 863 & 59.7 \\
\hline a Disease incidences were determined 1 \\
\multicolumn{3}{l}{ year after planting. }
\end{tabular}

velop longitudinal splits on the pseudostem just above the soil level. Internally, the vascular tissue shows reddish or brownish dots and streaks. Infection sometimes passes into young suckers through their attachment to infected parent rhizomes, as indicated by connecting discolored vascular strands (26).

Surface water and planting material are two major means for long-distance dispersal of the disease. During heavy rainfall, spores of the pathogen and infected tissues on the ground are carried in surface drainage water. These inocula infect plants along the irrigation ditches (Fig. 3).

Approximately 30 to $40 \%$ of suckers obtained from rhizomes of diseased banana plants are infected (26). Since infected suckers appear healthy, they have been used occasionally to plant new fields and have become sources for new infestations (Fig. 3). Cultural practices such as plowing before replanting and hoeing after planting also result in further spreading of the pathogen and in initiation of new infections. The pathogen can infect roots of certain weeds without causing visible symptoms and thereby perpetuate itself in the absence of banana $(27,31)$. The pathogen on infected weed roots also may initiate new infection on banana plants through the cultural practices mentioned above (Fig. 3). 


\section{Selection for Resistance Based on Somaclonal Variation}

Various methods have been tested to reduce populations of the pathogen in the field. Although some measures such as soil amendment with urea and rotation with paddy rice were effective, none were commercially acceptable $(8,26)$. Selection of resistant varieties is considered to be the best way of solving the Fusarium wilt problem. However, all commercial varieties tested were susceptible to race 4 of $F$. oxysporum f. sp. cubense (26). Conventional breeding to obtain commercially acceptable cultivars is a long-term endeavor. The fact that most cultivated bananas are triploids that rarely produce seeds makes the task even more difficult and time-consuming. During the search for a method to overcome this obstacle, we found a fast way of obtaining resistant cultivars for commercial planting based on somaclonal variation.

In order to prevent the spread of Fusarium wilt by infected planting material, more than one million Cavendish banana plantlets have been produced by tissue culture each year since 1984 at the Taiwan Banana Research Institute for commercial planting (10). Although Cavendish plants grown from suckers did not show any visible difference in morphology, about 3\% derived from tissue culture displayed variation in plant size, color of pseudostems and leaves, and shape of leaves and fruit (7). It was, therefore, considered possible that resistant clones might also exist among the tissue culture progeny as a result of somaclonal variation.

A project was consequently initiated in 1984 at the Taiwan Banana Research Institute to screen the Cavendish plantlets from tissue culture for resistance to Fusarium wilt. A 1-ha banana farm with about $60 \%$ incidence of Fusarium wilt in the previous year was chosen as the disease nursery. To hasten symptom development, diseased tissues were plowed into soil, giving the nursery a pathogen population of about 300 to 1,000 propagules per gram of soil throughout the testing period. Approximately 20,000 Cavendish plantlets from tissue culture were grown for 2 months in the screenhouse before being transplanted to the disease nursery. Symptoms of leaf yellowing and wilting began to appear on young banana plants within 3 months of transplantation. Only 45 plants remained healthy in appearance after 4 months. After 1 year, 27 more plants succumbed to the disease. Suckers from each of the 18 surviving clones were then collected, and their rhizomes were shaved with a knife to remove any infected tissues indicated by the presence of reddish or brownish streaks. Symptomless suckers were planted in the disease nursery again. All the first generation plants from suckers of six surviving clones remained healthy after 1 year

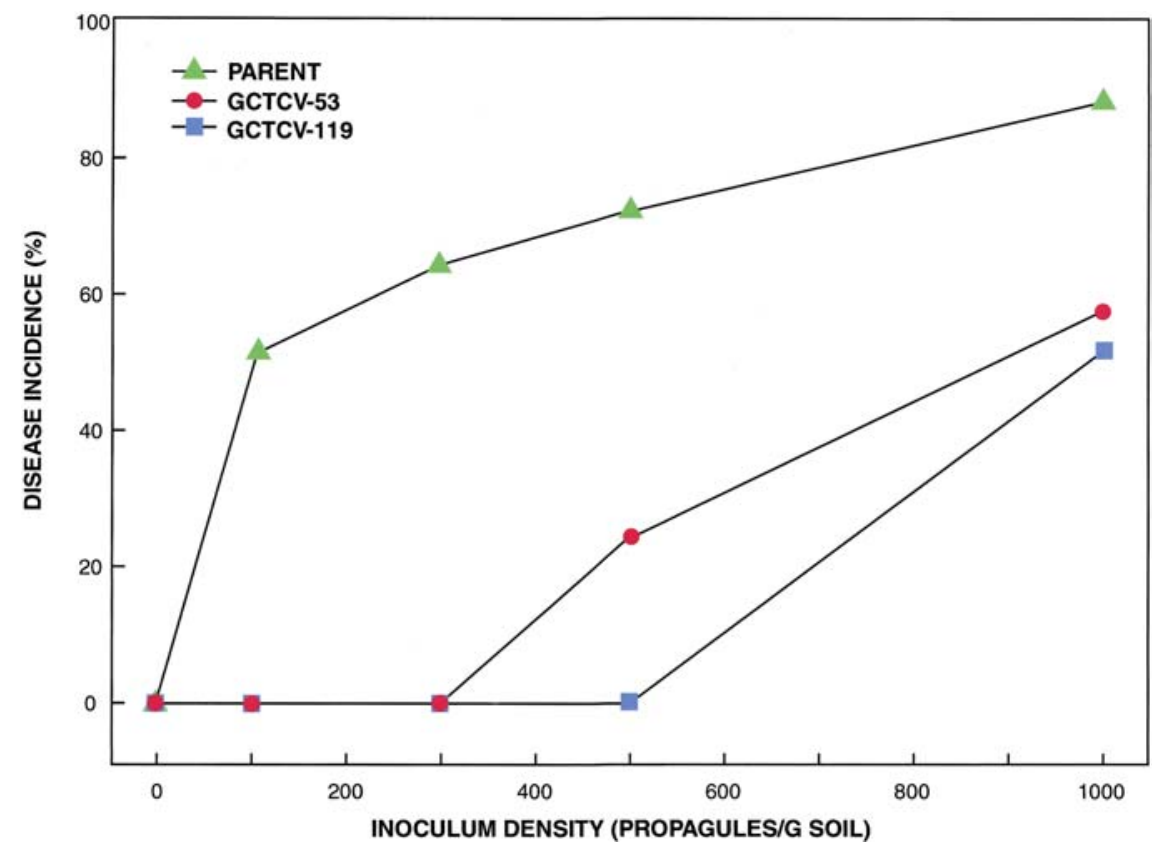

Fig. 5. Disease incidence of resistant somaclone in comparison with the susceptible Giant Cavendish parent in trays with various inoculum densities of race 4 of Fusarium oxysporum f. sp. cubense.

(Table 1). These clones were tested again immediately, while those clones with few infected suckers were saved for later tests.

The second- and third-generation suckers from the six resistant clones were processed and planted as described above. These suckers remained highly resistant to the pathogen in comparison with the suckers from the parent (Table 1) (11). Large numbers of plantlets were obtained from tissue cultures of all six resistant clones and planted in five infested banana farms. These plantlets were also highly resistant to the pathogen in comparison with those from the parent (Fig. 4, Table 2) (11).

Resistance also was tested in soil with controlled inoculum density in the screenhouse. Plantlets of resistant clones GCTCV-53, GCTCV-119, and the parent were planted in soils containing 0,100 , 300,500 , or 1,000 chlamydospores of the pathogen per gram of soil in plastic trays for 3 months. The experimental results were consistent with those obtained in the disease nursery and infested banana farms. The minimum inoculum densities needed to cause the disease on the parent, GCTCV-53, or GCTCV-119 clone were between 0 and 100, 300 and 500, and 500 and 1,000, respectively (Fig. 5) (11).

The resistant clones differed morphologically from the parent and possessed inferior horticultural characteristics, such as excessive height, weak petioles, and lengthened growth period (Table 3). Moreover, fruit bunches were smaller and fruits were lower in quality in comparison with the parent. However, when a large number of plantlets of resistant clones were planted in the infested field, some showed improved horticultural characteristics. One variant with improved bunch size was obtained from each of GCTCV-44, GCTCV-53, and GCTCV-119. The bunch weight produced by the variant GCTCV44-1 was increased from the original 13.8 to $21.5 \mathrm{~kg}$, close to the parental $25.9 \mathrm{~kg}$. The bunch weight of the variant GCTCV53-1 was increased from 13.8 to $21.5 \mathrm{~g}$, while that of GCTCV-119-1 was increased from 17.2 to $26.5 \mathrm{~kg}$, slightly heavier than that of the parent.

All of these improved variants retained their trait of resistance to Fusarium wilt (12). Unfortunately, these improved variants were not acceptable for commercial planting because, in comparison with the parental Giant Cavendish, the shelf life of bananas produced by GCTCV-44-1 was too short and the degreening time of fruit produced by GCTCV-53 and GCTCV-119 was too long.

\section{The Birth of a Commercially Acceptable Resistant Cultivar}

The search for resistant clones continued. Rhizomes of Giant Cavendish obtained from different locations were used to produce tissue culture plantlets to be tested for resistance to Fusarium wilt following the protocol described above. Six more resistant clones were obtained (Table 3). After further selection from the plantlets produced by these resistant clones, the variant GCTCV-215-1 was found to be a promising candidate for commercial planting. The average wilt incidences of GCTCV-215-1 and Giant Cavendish recorded at harvest were 9.5 and $49.1 \%$ (Fig. 6), respectively. In comparison with Giant Cavendish, GCTCV-215-1 grew about 18 $\mathrm{cm}$ taller and took 1 month longer to com- 
Table 3. Horticultural characteristics of Fusarium wilt resistant clones derived from Giant Cavendish by somaclonal variation

\begin{tabular}{lcl}
\hline Clone & Resistance $^{\mathbf{a}}$ & Horticultural characteristics $^{-}$ \\
\hline GCTCV-40 & High & Tall and slender pseudostem; weak petiole with narrow and drooping leaves; small bunch \\
GCTCV-44 & High & Short and slender pseudostem; weak petiole and drooping leaves; bunch normal but weak pedicel \\
GCTCV-46 & High & Black spots on pseudostem and leaf sheath; upright leaves; small bunch with short fingers \\
GCTCV-53 & High & Dark green pseudostem; drooping leaves; elongate male bud; small bunch with short fingers \\
GCTCV-62 & Moderate & Pale green pseudostem; fewer suckers; small bunch and fingers \\
GCTCV-104 & High & Pale green pseudostem; fewer fingers; long growth cycle \\
GCTCV-105 & High & Shorter and slender pseudostem; compact bunch with a greater number of short fingers \\
GCTCV-119 & High & Very tall; wavy leaves; short fruit stalk; long growth cycle; fewer hands but large fingers; sweeter fruit \\
GCTCV-201 & Moderate & Robust pseudostem; short fruit stalk; malformed hands \\
GCTCV-215 & High & Tall and slender pseudostem; leaf tip curl and splitting; fewer suckers; normal bunch but slender fingers; \\
GCTCV-216 & long growth cycle & \\
GCTCV-217 & High & Very tall; very large and heavy bunch; long growth cycle \\
\hline
\end{tabular}

${ }^{\mathrm{a}}$ High is $<10 \%$ average disease incidence; moderate is 11 to $30 \%$ average disease incidence. Disease incidences were determined 1 year after planting.
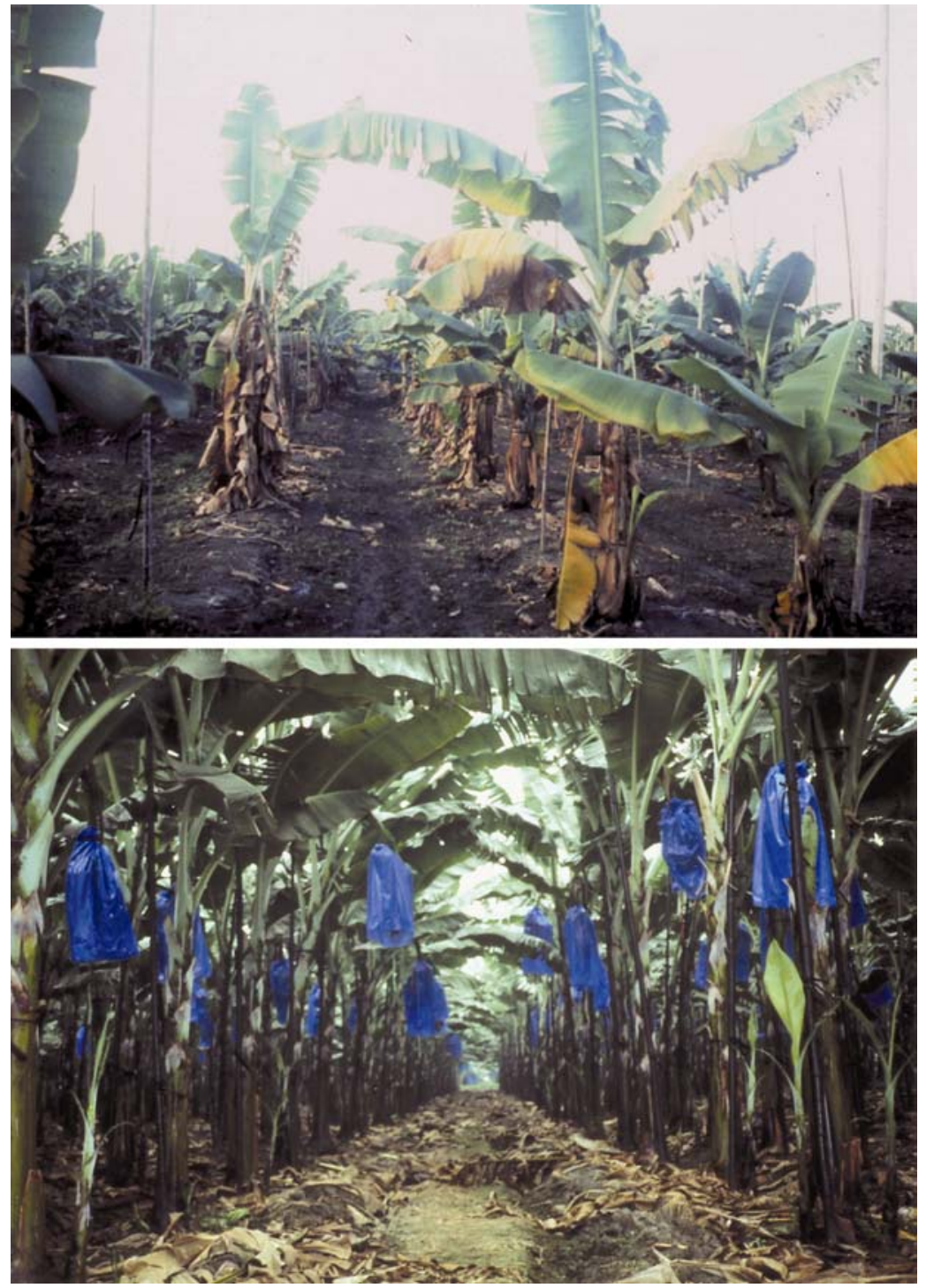

Fig. 6. Comparison of parental Giant Cavendish (upper) and Tai Chiao No. 1 (lower) planted in an infested orchard.

plete the growth cycle. Although the bunch produced by GCTCV-215-1 had about the same number of hands and fingers as that of Giant Cavendish, its bunch weight was slightly lighter because of relatively short and slender fingers (Table 4). From a marketing point of view, production of smaller hands by GCTCV-215-1 is an advantage because large banana hands are becoming less attractive to consumers in Taiwan and
Japan. The fruit of GCTCV-215-1 ripened normally after ethylene treatment, and their eating quality was as good as that of Giant Cavendish. The shelf life of fruit produced by these two cultivars was about the same.

About 80,000 plantlets of GCTCV-2151 were planted in 40 ha of infested orchards at various locations in 1990, the maximum hectarage allowed by the Taiwanese government for planting an unregistered variety. The results were very striking. The wilt incidences of GCTCV-215-1 were $17.2 \%$ for plantlets and $5.2 \%$ for suckers compared with $74.6 \%$ for plantlets and $77.8 \%$ for suckers of Giant Cavendish. The incomes of most Giant Cavendish growers surveyed were under the cost of production because of heavy losses to Fusarium wilt. However, growers who planted GCTCV-215-1 enjoyed a net profit averaging US $\$ 8,300$ per hectare (13).

In Taiwan, a new variety is required to be tested in the field for two seasons and to show the expected results each season before it can be registered for commercial planting. After witnessing the dramatic performance of GCTCV-215-1 in the first field trial, the growers' association sent a petition to the government requesting an emergency permit to allow all growers with the wilt problem to grow the unregistered GCTCV-215-1. The request was granted, and as a result, a total of 1.4 million GCTCV-215-1 plantlets were propagated and planted in 700 ha of infested orchards during the second season. GCTCV-215-1 again prevailed over the pathogen in the infested fields. The average wilt incidence of GCTCV-215-1 was only $4.8 \%$, compared with $39.1 \%$ on Giant Cavendish. Fruit produced by this resistant variant were well received by customers in both Taiwan and Japan. The variant was formally registered as cv. Tai Chiao No. 1 for commercial planting in 1992, 8 years after the initiation of the research project. From 1992 to 2001, between 1.6 and 3.0 million Tai Chiao No. 1 plantlets were planted on 800 to 1,500 ha of infested 
Table 4. Comparison of physiological and morphological characteristics between GCTCV-215-1 and Giant Cavendish ${ }^{\mathrm{a}}$

\begin{tabular}{|c|c|c|c|c|c|c|c|c|}
\hline Cultivar & $\begin{array}{c}\text { Wilt incidence } \\
(\%)\end{array}$ & $\begin{array}{c}\text { Plant } \\
\text { height } \\
(\mathrm{cm})\end{array}$ & $\begin{array}{c}\text { Pseudostem } \\
\text { girth }^{\mathbf{b}} \\
(\mathbf{c m})\end{array}$ & $\begin{array}{c}\text { Hand no./ } \\
\text { bunch }\end{array}$ & $\begin{array}{c}\text { Finger no./ } \\
\text { bunch }\end{array}$ & $\begin{array}{c}\text { Finger } \\
\text { length } \\
(\mathbf{c m})\end{array}$ & $\begin{array}{c}\text { Bunch } \\
\text { weight } \\
\text { (kg) }\end{array}$ & $\begin{array}{c}\begin{array}{c}\text { Growth } \\
\text { period } \\
\text { (months) }\end{array} \\
\end{array}$ \\
\hline GCTCV-215-1 & $4.8-17.2$ & 288 & 66.8 & 8.0 & 136.0 & 17.7 & 24.0 & 13 \\
\hline Giant Cavendish & $33.6-74.6$ & 270 & 70.5 & 7.9 & 136.8 & 18.5 & 26.3 & 12 \\
\hline
\end{tabular}

orchards each year (Fig. 7), representing about $75 \%$ of total infested orchards in Taiwan.

\section{Attempts to Improve the Resistant Cultivar}

The mature plants of Tai Chiao No. 1 are taller and more slender than those of Giant Cavendish and, hence, more susceptible to breakage by wind during the typhoon season. Tai Chiao No. 1 also has the disadvantages of requiring a longer time to complete the crop cycle and producing a lighter fruit bunch in comparison with Giant Cavendish. Therefore, other resistant variants with improved features were tested for possible adoption by growers and consumers. A variant of GCTCV-105 was shorter, more resistant to Fusarium wilt, and had a shorter growth cycle than Tai Chiao No. 1 and was comparable with Tai Chiao No. 1 in fruit yield (29). The variant was tested on growers' farms in 1995, but was discontinued the next year because its fruit were not acceptable to the Japanese market due to shorter shelf life. A variant of GCTCV-217 was also more resistant to Fusarium wilt than Tai Chiao No. 1. The fruit bunches produced by this variant were about $7 \%$ heavier than those produced by Tai Chiao No. 1 . This variant was tested in 1997, but was soon abandoned because its fruit did not receive favorable response in the Japanese market due to slower ripening rate.

An improved variant GCTCV-215-2 was selected from Tai Chiao No. 1; it was about $40 \mathrm{~cm}$ shorter than Giant Cavendish and was therefore much easier to harvest and more resistant to destruction by strong wind. Its level of resistance, growth cycle, and yield were close to the parental Tai Chiao No. 1. Unfortunately, during the pilot trials, the variant was found to be very sensitive to environmental stresses. The yield decreased considerably in less fertile soils, and the variant frequently showed abnormal emergence of inflorescences (choking) in areas with cold winters. The tests were, therefore, discontinued after 2 years.

\section{Formosana: A New Generation Resistant Cultivar}

Around 1990, a Taiwan farmer named Mr. Chung Hwang obtained from his neighbor some suckers produced by plants

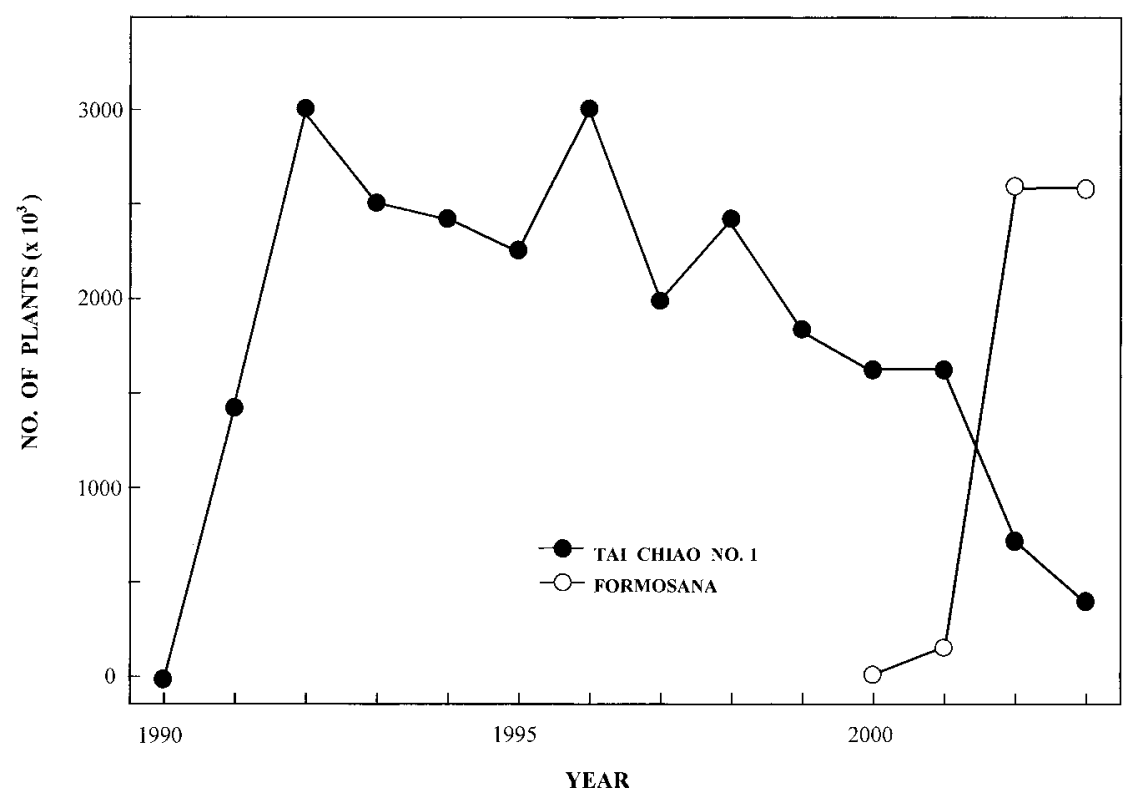

Fig. 7. Numbers of plants of resistant Giant Cavendish cultivars Tai Chiao No. 1 and Formosana planted in Taiwan from 1990 to 2003.

grown from tissue culture plantlets of Giant Cavendish provided by the Taiwan Banana Research Institute for planting on the bank of an irrigation ditch. New suckers produced by these plants were dug up and planted in the new area on the bank. As expected, Fusarium wilt appeared in the second year, and the disease incidence increased each year. In 1993, the farmer noticed that among so many diseased plants, some remained very strong and healthy. He traced them back and found all of them originated from one of the original suckers. Suckers produced by this clone were therefore used to replace the diseased plants. All of them grew to maturity without showing any disease symptoms, and the fruit bunches produced by them appeared to be larger than those produced by the parental Giant Cavendish. He informed the director of the Taiwan Banana Research Institute of his discovery in 1997. The observation was confirmed experimentally in the following years, and the clone was designated GCTCV-218.

The average wilt incidence of GCTCV218 was $4.1 \%$, significantly lower than 9.5\% of the resistant Tai Chiao No. 1 and $29.6 \%$ of the susceptible Giant Cavendish (Fig. 8). The new clone also surpasses the latter in horticultural characteristics such as having more robust pseudostem, stronger petioles, thicker leaves, better hand formation, and more uniform hand size. The growth cycle of GCTCV-218 was the same as that of Tai Chiao No. 1, about 1 month longer than that of Giant Cavendish. However, the fruit bunches produced by GCTCV-218 were about $50 \%$ heavier than those produced by Giant Cavendish (Fig. 9), important in banana improvement (9).

Soon other banana growers started to obtain suckers of GCTCV-218 from farmer Hwang for planting in their own orchards. The first field trial consisted of 40 ha planted with tissue culture plantlets of GCTCV-218 provided by the Taiwan Banana Research Institute in 2000. Suckers from farmer Hwang planted by other growers on 20 ha of their orchards were also included in the survey. Results were very impressive. GCTCV-218 showed low wilt incidence and high yield in all the infested orchards surveyed. Its fruit were of high quality and received favorable response from both local and Japanese markets. Similar results were obtained in the second trial carried out the following year. Subsequently, GCTCV-218 was registered as cv. 

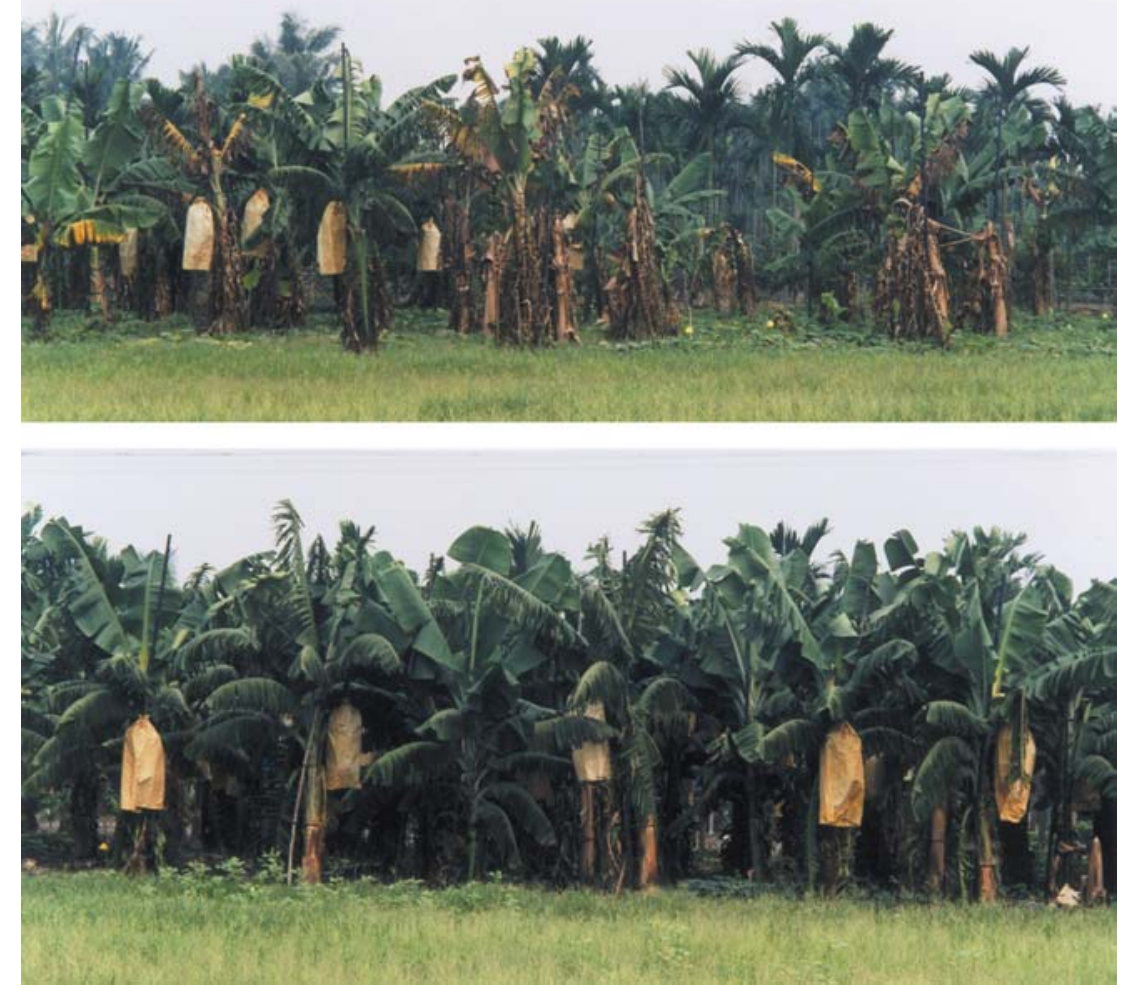

Fig. 8. Comparison of parental Giant Cavendish (upper) and Formosana (lower) planted in an infested orchard.
Formosana in 2002, and 2.6 million plantlets of this new cultivar were produced for commercial planting. The same number of Formosana plantlets were planted in 2003. Formosana has rapidly replaced Tai Chiao No. 1 for commercial planting in infested orchards in Taiwan (Fig. 7).

\section{Current Status and Future Outlook}

We have demonstrated the feasibility of using tissue culture to generate variation for selection of commercially acceptable wilt resistant cultivars of Giant Cavendish. The technique is simple and quick for obtaining a desired trait. The growth cycle for Giant Cavendish is 1 year, and the first wilt resistant cultivar acceptable for commercial planting was obtained within only 6 years of research. The selected trait is very stable, as the level of resistance of Tai Chiao No. 1 against Fusarium wilt has not changed in more than 10 years of planting under various environmental conditions. Recently, the technique has also been used in South Africa (5) and Malaysia (6) to obtain Fusarium wilt resistant clones of their own banana cultivars.

Cultivar Formosana is not perfect. Therefore, the selection process is still in progress in Taiwan. Like the parental Giant Cavendish, fruit produced by Formosana are susceptible to damage by thrips, and
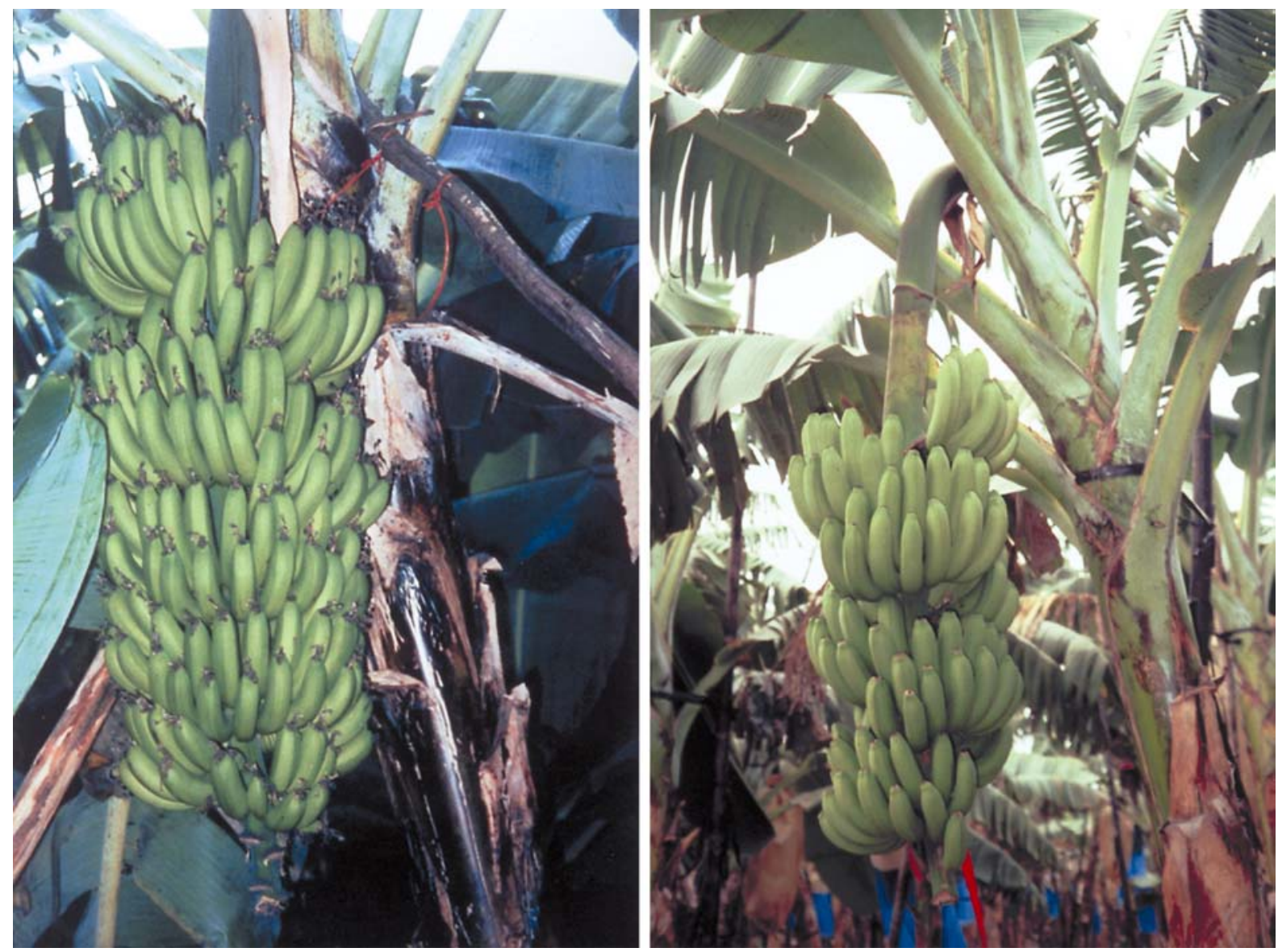

Fig. 9. Comparison of fruit bunches produced by Formosana (left) and Giant Cavendish (right). 
rubbery fruit still appear sporadically in the early spring. Environmental stresses have considerable effect on Fusarium wilt incidence of all the resistant somaclones, including Formosana. Under unfavorable environmental conditions such as poor drainage and sandy soil, wilt incidence on resistant somaclones sometimes reached as high as $30 \%$. These problems need to be overcome.

In vitro propagation produces banana clones that are very diverse. For Giant Cavendish, in addition to resistance to Fusarium wilt, the tissue culture method also generated clones with increased resistance to strong wind, heavier fruit bunches, and sweeter fruit. Therefore, it may be an ideal procedure for horticulturists to select banana clones producing fruit with different taste and might be possible for plant pathologists to select clones resistant to other important diseases. The possibility of applying this technique to the improvement of other crops remains to be exploited.

Although 40,000 Cavendish plants grown from suckers did not show any visible difference in morphology, about $3 \%$ of Cavendish plantlets derived from tissue culture were variants (26). Relatively little is known about the cause of genetic instability induced by the in vitro vegetative propagation (17). Rapid multiplication and development of cells resulting from mediation of regulators in the tissue culture medium may increase the chance of variation. The mechanism by which the somaclones of Giant Cavendish are resistant to Fusarium wilt is unknown. Since the parental Giant Cavendish is very susceptible to Fusarium wilt, the appearance of resistant somaclones may result from activation of silent resistant genes. However, the creation of resistance genes through mutation as the origin of the resistant phenotype cannot be ruled out. DNA technology will be useful in deciphering the true nature of wilt resistance in the future.

\section{Acknowledgments}

We thank Jyh-Nong Tsai, Hsiu-Fang Cheng, and Chyong-Yueh $\mathrm{Hu}$ for preparation of figures. This research was supported in part by grants from the Council of Agriculture and the National Science Council of Taiwan.

\section{Literature Cited}

1. Ashby, S. F. 1926. Panama disease in the Canaries and West Africa. Trop. Agric. 3:8.

2. Bentley, S., Pegg, K. G., Moore, N. Y., Davis R. D., and Buddenhagen, I. W. 1998. Genetic variation among vegetative compatibility groups of Fusarium oxysporum f. sp. cubense analyzed by DNA fingerprinting. Phytopathology 88:1283-1293.

3. Conde, B. D., and Pitkethley, R. N. 2001. The discovery, identification and management of banana fusarium wilt outbreaks in the Northern Territory of Australia. Pages 260-265 in: Banana Fusarium Wilt Management: Towards Sustainable Cultivation. A. B. Molina, N. H. Nik Masdek, and K. W. Liew, eds. International Network for the Improvement of Banana and Plantain/The Asia and Pacific Network, Los Banos, Laguna, Philippines.

4. Davis, R. I., Moore, N. Y., Bentley, S., Gunua, T. G., and Rahamma, S. 2000. Further records of Fusarium oxysporum f. sp. cubense from New Guinea. Aust. Plant Pathol. 29:224.

5. De Beer, Z. C., Severn-Ellis, A., and Husselman, J. H. 2001. Preliminary assessment of Cavendish banana clones for resistance/tolerance to fusarium wilt. Pages 194-200 in: Banana Fusarium Wilt Management: Towards Sustainable Cultivation. A. B. Molina, N. H. Nike Masdek, and K. W. Liew, eds. International Network for the Improvement of Banana and Plantain/The Asia and Pacific Network, Los Banos, Laguna, Philippines.

6. Ho, Y. W., Mak, C., and Liew, K. W. 2001. Selection of banana cultivars for tolerance to fusarium wilt race 4 in Malaysia. Pages 234242 in: Banana Fusarium Wilt Management: Towards Sustainable Cultivation. A. B. Molina, N. H. Nike Masdek, and K. W. Liew, eds. International Network for the Improvement of Banana and Plantain/The Asia and Pacific Network, Los Banos, Laguna, Philippines.

7. Hwang, S. C. 1986. Variation in banana plants propagated through tissue culture. J. Chin. Soc. Hortic. Sci. 32:117-125.

8. Hwang, S. C. 1990. Somaclonal resistance in Cavendish banana to fusarium wilt. Pages 121125 in: Fusarium Wilt of Banana. R. C. Ploetz, ed. American Phytopathological Society, St. Paul, MN.

9. Hwang, S. C. 2001. Recent development on fusarium R \& D of banana in Taiwan. Pages 39-49 in: Banana Fusarium Wilt Management: Towards Sustainable Cultivation. A. B.
Molina, N. H. Nik Masdek, and K. W. Liew, eds. International Network for the Improvement of Banana and Plantain/The Asia and Pacific Network, Los Banos, Laguna, Philippines.

10. Hwang, S. C., Chen, C. L., Lin, J. C., and Lin, H. L. 1984. Cultivation of banana using plantlets from meristem culture. HortScience 19:231-233.

11. Hwang, S. C., and Ko, W. H. 1988. Mutants of Cavendish banana resistant to race 4 of $\mathrm{Fusa}$ rium oxysporum f. sp. cubense. Plant Prot Bull. (Taiwan) 30:386-392.

12. Hwang, S. C., and Ko, W. H. 1989. Improvement of fruit quality of Cavendish banana mutants resistant to race 4 of Fusarium oxysporum f. sp. cubense. Plant Prot. Bull. (Taiwan) 31:131-138.

13. Hwang, S. C., Ko, W. H., and Chao, C. P. 1994. GCTCV-215-1: A promising Cavendish clone resistant to race 4 of Fusarium oxysporum f. sp. cubense. Plant Prot. Bull. (Taiwan) 36:281-291.

14. Lee, Y. M., Teo, L., and Ong, K. P. 2001. Fusarium wilt of Cavendish banana and its control in Malaysia. Pages 252-259 in: Banana Fusarium Wilt Management: Towards Sustainable Cultivation. A. B. Molina, N. H. Nik Masdek, and K. W. Liew, eds. International Network for the Improvement of Banana and Plantain/The Asia and Pacific Network, Los Banos, Laguna, Philippines.

15. Magnaye, L. V. 2001. Status of Panama disease in the Philippines. Page 50-57 in: Banana Fusarium Wilt Management: Towards Sustainable Cultivation. A. B. Molina, N. H. Nik Masdek, and K. W. Liew, eds. International Network for the Improvement of Banana and

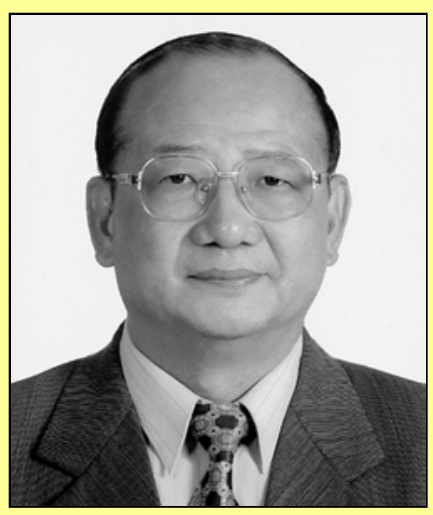

Shin-Chuan Hwang

Dr. Hwang is a plant pathologist and director of the Taiwan Banana Research Institute. He received his B.S. degree from National Taiwan University and his M.S. and Ph.D. degrees from the University of Hawaii. His research interests cover all aspects of banana diseases, with special emphasis on Fusarium wilt. He was elected as one of the Ten Outstanding Young Men of the nation in 1982, received the Distinguished Agricultural Research and Extension Award from the Council of Agriculture of Taiwan in 1988, and was bestowed the Outstanding Applied Science and Technology Award by the National Science Council of Taiwan in 1992.

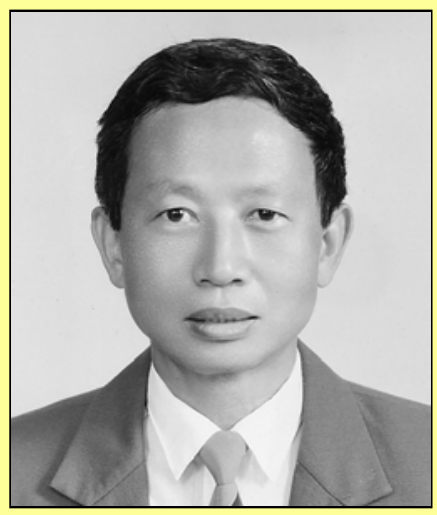

Wen-Hsiung Ko

Dr. Ko is professor of plant pathology at Beaumont Agricultural Research Center of the University of Hawaii at Manoa. He received his B.S. degree from National Taiwan University and his Ph.D. degree from Michigan State University. His research interests include ecology and biological control of soilborne diseases of tropical fruit crops and biology of Phytophthora. He received the Ruth Allen Award in 1984 from the American Phytopathological Society for his contribution in hormonal regulation of sexual reproduction in Phytophthora and is a Fellow of the American Phytopathological Society. 
Plantain/The Asia and Pacific Network, Los Banos, Laguna, Philippines.

16. Moore, N. Y., Bentley. S., Pegg, K. C., and Jones, D. R. 1995. Fusarium wilt of banana. Musa Disease Fact Sheet No. 5. International Network for the Improvement of Banana and Plantain/The Asia and Pacific Network, Los Banos, Laguna, Philippines.

17. Pierik, R. L. M. 1987. In Vitro Culture of Higher Plants. Martinus Nijhoff Publishers, Dordrecht, The Netherlands.

18. Ploetz, R. C., Herbert, J., Sebasigari, K., Hernandez, J. H., Pegg, K. G., Ventura, J. A., and Mayato, L. S. 1990. Importance of fusarium wilt in different banana growing regions. Pages 9-26 in: Fusarium Wilt of Banana. R. C. Ploetz, ed. American Phytopathological Society, St. Paul, MN.

19. Ploetz, R. C., and Pegg, K. G. 2000. Fusarium wilt. Pages 143-159 in: Diseases of Banana, Abaca and Enset. D. R. Jones, ed. CABI Publishing, Wallingford, UK.

20. Qi, P. 2001. Status report of banana fusarium wilt disease in China. Pages 119-120 in: Banana Fusarium Wilt Management: Towards
Sustainable Cultivation. A. B. Molina, N. H. Nik Masdek, and K. W. Liew, eds. International Network for the Improvement of Banana and Plantain/The Asia and Pacific Network, Los Banos, Laguna, Philippines.

21. Sabadell, S., and Hernandez, J. M. 2001. Panama disease and a similar disorder ('False $\mathrm{Pa}$ nama') in the Canary Islands. Pages 266-274 in: Banana Fusarium Wilt Management: Towards Sustainable Cultivation. A. B. Molina, N. H. Nik Masdek, and K. W. Liew, eds. International Network for the Improvement of Banana and Plantain/The Asia and Pacific Network, Los Banos, Laguna, Philippines.

22. Simmonds, N. W. 1966. Bananas. 2nd ed. Longmans, London.

23. Stover, R. H. 1962. Fusarial Wilt (Panama Disease) of Bananas and Other Musa Species. Phytopathol. Pap. 4. Commonw. Mycol. Inst., Kew, Surrey, England.

24. Stover, R. H. 1972. Banana, Plantain and Abaca Diseases. Commonw. Mycol. Inst., Kew, Surrey, England.

25. Su, H. J., Chuang, T. Y., and Kong, W. S. 1977. Physiological race of fusarial wilt fungus at- tacking Cavendish banana of Taiwan. Taiwan Banana Res. Inst. Special Pub. 2:1-21.

26. Su, H. J., Hwang, S. C., and Ko, W. H. 1986. Fusarial wilt of Cavendish bananas in Taiwan. Plant Dis. 70:814-818.

27. Sun, E. J. 1977. Survival of race 4 of Fusarium oxysporum f. sp. cubense in the soil. M.S. thesis. National Taiwan University, Taipei.

28. Sun, E. J., Su, H. J., and Ko, W. H. 1978 Identification of Fusarium oxysporum f. sp. cubense race 4 from soil or host tissue by cultural characteristics. Phytopathology 68:16721673.

29. Sun, P. M. H., Hwang, S. C., and Ko, W. H. 1996. GCTCV-105, a new Cavendish somaclone highly resistant to fusarium wilt with commericial potential. Plant Prot. Bull. (Taiwan) 38:27-37.

30. Sun, S. K. 2001. Diseases of Fruit Trees in Taiwan. Suwei Pub. Co., Taichung, Taiwan. In Chinese.

31. Waite, B. H., and Dunlap, V. C. 1953. Preliminary host range studies with Fusarium ox ysporum f. sp. cubense. Plant Dis. Rep. 37:7980 